\title{
EDITORIAL
}

\section{Introduction to the Special Section}

\section{DANTE CICCHETTI}

University of Minnesota

The inaugural symposium celebrating the opening of the University of Minnesota's Institute for Translational Research in Children's Mental Health (ITR) was held May 13, 14, and 15, 2015, in the Hubert Humphrey Center on the Minneapolis campus of the University of Minnesota. The ITR is an interdisciplinary center, and one of its missions is to conduct basic and applied multilevel research investigations on aspects of child and adolescent mental health that are translated into the development and implementation of theoretically informed randomized control trial evidence-based interventions. The core faculty of the ITR are Professors
Abi Gewirtz (Director), Dante Cicchetti (Research Director), and Gerald August (Director of Training and Education). This inaugural symposium, titled "Epigenetics: Development, Psychopathology, Resilience, and Preventive Intervention," hosted an extraordinary list of speakers, each of whom has submitted a paper to this Special Section of Development and Psychopathology.

We would be remiss if we did not acknowledge the contributions of our mentor, colleague, and dear friend, Irv Gottesman (December 29, 1930-June 29, 2016), in his magnificent role as the moderator of the Speaker Panel Discussion.

The symposium was funded through the Klaus J. Jacobs Prize awarded to Dante Cicchetti by the Jacobs Foundation (http://jacobsfoundation.org/de/). Address correspondence and reprint requests to: Dante Cicchetti, Institute of Child Development, 51 East River Road, University of Minnesota, Minneapolis, MN 55455; E-mail: cicchett@umn.edu. 